\title{
Temas e Debates para a HISTÓRIA DO BRASIL \\ A Contribuição DE E.P. Thompson ${ }^{1}$
}

\author{
José Carlos Barreiro
}

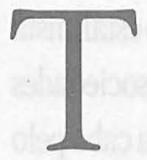

hompson, por sua história de militância e pelos inúmeros debates travados com intelectuais de elevada estatura, dentro e fora do partido comunista portanto, numa das maiores expressões da historiografia mundial. Contudo, o surgimento do pensamento de Thompson não está desvinculado das configurações políticas de seu próprio presente. Nesta perspectiva, torna-se imperativo relacioná-lo aos principais acontecimentos do cenário político mundial. Não se quer com isso repor a velha correspondência mecânica entre a produção das idéias e o determinismo de seu tempo. Contudo, não se chega a uma reflexão fecunda a não ser libertando-se de uma história desencarnada que institui um universo de abstrações sem limites para o próprio pensamento. ${ }^{3}$ Nesse sentido, se não isolarmos o conjunto das idéias de Thompson, das formas de vida social que o produziu, é possível perceber que ele foi profundamente marcado pela emergência das contradições que abalaram progressivamente o sistema totalitário do mundo socialista a partir dos anos 30 do século passado, e, sobretudo dos anos 50. Nessa conjuntura, no que diz respeito aos principais acontecimentos internacionais, discutiam-se, entre outros temas, a Guerra Fria, os processos de Moscou, a divulgação da existência de campos de concentração na URSS. 0 socialismo real e a política dos Partidos Comunistas passaram a ser questionados, porque nada diziam que pudesse anuviar a reputação socialista do regime soviético ou dos regimes dos países do leste. Não deram ao protesto dos dissidentes a ampla ressonância que estavam em condições

1 Este artigo foi gerado a partir do projeto de pesquisa "Formas rituais e simbólicas da dominação e do protesto popular. Brasil, 1780-1880", em desenvolvimento.

2 Doutor em História pela USP. Professor livre-docente do Departamento de História da Unesp/Assis. Autor do livro Imaginário e Viajantes no Brasil do Século XXX: Cultura e Cotidiano, Tradição e Resistência. Editora Unesp, 2003.

3 Cf. CharTIER, R. A História Cultural: entre práticas e representações. Lisboa: Difel, 1990. p. 34 s. 
de dar. Longe de informar ou instruir seu público, dissimulavam e soterravam a questão do estalinismo e a natureza do Estado totalitário. ${ }^{4}$

Este quadro de crise do socialismo e da política dos partidos de esquerda estimulou a emergência de alguns grupos ou escolas importantes que dariam contribuições duradouras para a renovação do conhecimento humanístico e do conhecimento histórico em particular. Na França, por exemplo, não se pode ignorar as contribuições do grupo vinculado à Filosofia Política Francesa Contemporânea - dentre eles Merleau Ponty, Claude Lefort e Cornelius Castoriadis - e dos historiadores vinculados à Nova História. ${ }^{5}$ Todavia, o pensamento de Thompson surgiria em meio aos movimentos importantes que emergiam na Inglaterra naquele momento. A contestação ao mecanicismo estalinista que subordinava a interpretação histórica aos cinco modos sucessivos que as sociedades humanas deveriam necessariamente percorrer, e as discussões internas levadas a cabo pelo Partido Comunista Inglês, fez surgir, por exemplo, a obra de Maurice Dobb reformulando de forma inovadora a questão da transição do feudalismo ao capitalismo, bem como as grandes contribuições de historiadores como Christopher Hill, Eric Hobsbawm, Raphael Samuel edo próprio Edward Thompson, entre outros. Muitos desses historiadores reuniramse em torno da New Left Review criada em 1957 abrigando debates criativos, até pelo menos 1963, quando Perry Anderson assume a direção da revista e Thompson marca seu rompimento com o grupo escrevendo o seu The Making of the English Working Class. Outros grupos igualmente vigorosos surgem na Inglaterra como, por exemplo, o grupo History Workshop, nascido no Ruskin College, de 0xford, em 1966. Este grupo se constituiu em torno da figura de Raphael Samuel. Propondo-se a lutar contra o sistema tradicional de exames e a dar uma participação ativa no estudo da história aos estudantes da classe operária, o grupo publica uma série de panfletos entre 1970 e 1974, que origina, em 1976, a History Workshop Journal, revista que consegue suscitar o debate em torno das questões contemporâneas de modo não ortodoxo, por engajar não só historiadores preocupados com os problemas atuais, mas também setores do movimento operário e de outros movimentos populares como o feminismo.

Em meio à efervescência dessas idéias, Thompson, na condição de historiador marxista, levou a cabo inúmeros avanços em relação ao tratamento dado à questão da

Cf. Lefort, C. A invenção democrática. São Paulo: Brasiliense, 1983. p. 15ss.

5 Burke, P. "El 'descobrimiento' de la cultura popular". In: SAmuel, R. (ed.) História popular y teoria socialista. Barcelona: Editorial Crítica, 1984. 
teoria e dos conceitos no materialismo histórico. Tais questões iam no sentido de que a teoria, na sua relação com as evidências empíricas, envolve uma exploração aberta do mundo que supõe a recusa da decretação de certezas prévias em relação ao fazer socialhistórico. Neste sentido, Thompson rompe, sob muitos aspectos, com o determinismo das análises fundadas no materialismo histórico, substancialmente presente em autores marxistas à época em que produziu seus trabalhos mais vigorosos. Thompson tornou, portanto, o marxismo mais criativo enquanto teoria e conceitos operacionalizáveis.

\section{A Conjuntura do Brasil}

Os trabalhos de E.P. Thompson têm sido divulgados no Brasil há cerca de duas décadas. É hora de iniciarmos uma reflexão mais atenta acerca de sua influência na produção do conhecimento histórico nacional. Parece oportuno conduzir esta reflexão à luz do avanço proporcionado por Thompson em relação ao tratamento dado pelo marxismo ao problema da cultura. Thompson avançou neste ponto, em relação ao marxismo da época, graças ao seu diálogo com a Antropologia e, também, graças à incorporação à sua obra, das reflexões de Gramsci sobre o conceito de hegemonia.

Nos anos 1970 a sociedade brasileira viveu a emergência dos movimentos sociais ressurgidos dos escombros da ditadura militar. Os movimentos de massa anteriores à implantação do regime militar não haviam desaparecido, mas a repressão confinou-os a uma existência subterrânea. Quando vieram à tona, apresentaram-se com características novas, a ponto de escapar inteiramente aos padrões de inteligibilidade teórica ditados pela velha esquerda. Como entender as significações novas, os novos tipos de motivações, os novos valores, as novas formas de luta dos movimentos populares dos anos 70 a partir de concepções teóricas que reduziam a riqueza e complexidade da atividade humana à determinação das forças produtivas? Certamente, seria impossível entender os novos movimentos sociais, fundamentandose em conceitos rígidos da esquerda tradicional vinculada aos partidos da época, conceitos estes que também embasavam a produção do conhecimento histórico de historiadores importantes da sociedade brasileira.

Assim, surpreendidos a cada dia pela irreverência e autonomia do sindicalismo e dos movimentos de massa em geral, e, impossibilitados de explicar seu comportamento a partir de conceitos inflexíveis, muitos militantes, intelectuais e historiadores descobriram a obra de Thompson. As dificuldades iniciais de acesso aos seus textos foram vencidas pela 
necessidade de se entender uma realidade nova que parecia fazer mais sentido à luz das concepções teóricas da History from Below ${ }^{6}$ partilhadas e amplamente desenvolvidas por Thompson e seus companheiros da New Left.

A partir da leitura dos trabalhos de Thompson, alguns setores da historiografia brasileira adentraram o complicado terreno das relações do marxismo com a cultura, para, a partir daí, recompor a memória cultural das "camadas populares". Isto significou, ao mesmo tempo, questionar a perspectiva que concebe os homens como produtos de forças materiais que os determinam por completo. Com o exercício thompsoniano de introduzir a questão da cultura como fenômeno importante do materialismo histórico foi possivel recuperar as teses de Marx contra Feuerbach e, com elas, a idéia revolucionária de que o povo se educa a partir de sua própria práxis. Por conseguinte, foi possível resgatar também a concepção segundo a qual os homens constituem-se em sujeitos de sua própria história, e modificam continuamente as circunstâncias em que vivem e se transformam. ${ }^{8}$ Elenquemos, então, alguns temas sobre os quais a contribuição de Thompson parece ser bastante visível, e outros em que se podem vislumbrar possibilidades de avanço em direção a novas pesquisas.

\section{A Historiografia e o Tema da Escravidão}

Os estudos brasileiros que refletiram sobre as camadas populares, a partir de seu universo de cultura, quase sempre evocavam este tema, não para investigar a sua condição de sujeito, mas para desenvolver a idéia de passividade. 0 tema da escravidão, por exemplo, surge nas interpretações clássicas, a partir da comparação com a escravidão antiga, para acentuar que os escravos da Antigüidade eram culturalmente superiores aos seus conquistadores, enquanto no Brasil eles eram de nível cultural ínfimo, porque provinham de povos bárbaros, arrancados de seu habitat natural e incluídos, sem transição, numa civilização que a eles era inteiramente estranha. Sob esse ponto de vista, a contribuição do escravo negro ou índio era vista como passiva e quase nula.?

\footnotetext{
"História concebida a partir das perspectivas dos segmentos populares".

Cf. Fenelon, D. R. E. P. Thompson - História e Política. Projeto História. Revista do Programa de Estudos PósGraduados em História da PUC-SP. São Paulo, 1981. pp. 77-93.

8 Cf. BarReiro, J.C. O Materialismo Histórico e a questão da Cultura. Revista Brasileira de História, 19, São Paulo, Anpuh, 1990, pp. 209-218.

9 Cf. Prado Jr, C. Evolução Política do Brasil e outros estudos. São Paulo: Brasiliense, 1977. p. 273.
} 
É claro que faltava a essas interpretações o entendimento de que a dinâmica da relação entre culturas subordina-se a um processo que envolve criação e luta. ${ }^{10}$ Porém, mais do que isso, o problema dessas considerações é que elas orientavam-se na direção de tratar a cultura como "coisa", isto é, como algo que é criado pelos dominantes e simplesmente internalizado pelas "camadas populares". Ademais, o conceito de cultura parece que tomava como fundamento uma "fixação etnocentrista" na qual tudo é definido a partir da idéia de "civilização". Esta idéia, por sua vez, é constituída pela "convicção complementar de que a história tem um sentido único, de que toda a sociedade está condenada a inscrever-se nesta história e a percorrer as suas etapas que a partir da selvageria, conduzem à civilização". ".

Thompson conseguiu produzir um resultado teórico mais dinâmico ao analisar a plebe inglesa do século XVIII. Tal resultado decorre do conceito de cultura utilizado como ponto de partida para analisar as lutas sociais do período. Sua concepção de cultura vincula-se ao conceito de experiência, que incorpora múltiplas evidências de vida ou de arte dos homens, evidências estas tratadas no plano de sua consciência, das maneiras as mais complexas, para em seguida agirem sobre as situaçoes determinadas. Thompson examina, então, para apreender a vida social a partir da perspectiva da "experiência humana", os sistemas densos e complexos vinculados à relações de parentesco e aos costumes; inclui na análise as regras visíveis e invisíveis da dominação social, as formas simbólicas de dominação e resistência, fé religiosa e impulsos milenaristas. Os costumes, por exemplo, como elementos integrantes das definições consuetudinárias da plebe inglesa do século XVIII, serviam para que ela mostrasse a dimensão rebelde da sua cultura tradicional às inovações e racionalizações por ela experimentadas como exploração, expropriação de direitos de aproveitamentos tradicionais ou denegação violenta de modelos valorativos de trabalho e descanso. A expressão simbólica aparece como mecanismo particularmente importante do comportamento da plebe em relação à igreja ou à nobreza, como éo caso, por exemplo, do simbolismo do nabo e dos cornos, usado jocosamente para definir a relação da plebe com o rei Jorge I. Pode-se perceber, pois, que o termo "cultura", básico no desenvolvimento do conceito de "experiência humana" e na recuperação dos elementos fundamentais para a reconstituição do confronto entre a plebe e a gentry, fundamenta-se na melhor tradição teórica dos estudos antropológicos utilizados por

${ }^{10}$ Cf. Samuel, R. (ed.) História popular y teoria socialista. Barcelona: Editorial Crítica, 1984. p. 89ss.

${ }^{11}$ A expressão "fixação etnocentrista" é usada por Pierre Clastres ao criticar as análises das sociedades primitivas, efetuadas a partir de enfoques evolucionistas, que privilegiam idéias provindas do campo ideológico do Ocidente. Cf. Clastres, P. A Sociedade contra o Estado. Rio de Janeiro: Francisco Alves, 1978. pp. 132-152. 
Thompson. Ao invés de jogar com a dicotomia civilização versus barbárie, 0 autor reconstitui a dinâmica da vida social a partir do conjunto de normas, valores, obrigações, expectativas e tabus existentes em cada um dos grupos sociais. ${ }^{12}$

Evidentemente, a partir dessas concepções de Thompson, alguns estudos sobre escravidão no Brasil passaram a enfatizar a cultura africana em sua multiplicidade, complexidade e especificidade, não mais a avaliando por comparação com a "civilização" européia. Para isto contribuiu também a discussão de Thompson a respeito da operacionalidade analítica do termo "paternalismo", em substituição a termos genéricos como "feudal", "capitalista" ou "patriarcal", o que o ampara na crítica às análises tradicionais da sociedade inglesa do século XVIII, que a apresentavam como uma sociedade consensual.

Estes foram pontos fundamentais buscados por alguns autores para procederem à critica da historiografia da escravidão dos anos 1960/70. Nestes anos, a historiografia construiu a imagem de um mundo governado pelos interesses senhoriais, no qual a dominação sobre a massa escrava era opressiva e violenta. A ênfase na violência e na análise dos interesses econômicos da escravidão conduzia tais reflexões a privilegiar a visão senhorial e a excluir os escravos.

Recorrendo, portanto, ao conceito de cultura e à discussão sobre o termo paternalismo, os historiadores começam a insistir na necessidade de incluir a experiência escrava na história da escravidão no Brasil. As análises passaram a evidenciar que, se por um lado, os senhores consideravam os escravos como "coisas" ou seres destituídos de vontade própria, por outro, os próprios escravos emergiam na cena social como homense mulheres que impunham limites à vontade senhorial. Eles possuíam projetos e idéias próprias pelos quais lutavam e conquistavam pequenas e grandes vitórias, que os senhores não reconheciam, porque se tratava, para eles, de generosas e paternais concessões. Contudo, os escravos traduziam esse paternalismo numa doutrina diferente da imaginada pelos senhores, e as concessões senhoriais transformavam-se em conquistas obtidas duramente devendo, portanto, serem mantidas como direitos. ${ }^{13}$

${ }^{12}$ Cf. Thompson, E.P. Tradición, revuelta y consciencia de clase. Barcelona: Editorial Crítica, 1979. pp .45-53.

${ }^{13}$ Cf. LARA, S.H. Blowin's in the Wind. E.P. Thompson e a experiência negra no Brasil. Projeto História, 12, 1995, pp. 43-56; Idem Campos da Violência: escravos e senbores na Capitania do Rio de Janeiro (1750-1808). Rio de Janeiro: Paz e Terra, 1988; Ress, J. J. Rebelião Escrava no Brasil: a bistória do levante dos Malês. São Paulo: Brasiliense, 1986; CHAнноив, S. Visões da Liberdade. Uma História das últimas décadas da escravidão na Corte. São Paulo: Companhia das Letras, 1990. 


\section{Políticas e Imaginários}

Se em relação à escravidão os trabalhos de Thompson estimularam inovações importantes, é preciso lembrar outros aspectos da história do Brasil que ainda estão à espera de uma revisão. É este o caso do tratamento que tem sido dado ao estudo do homem comum, sua cultura esua relação com as elites dominantes, a partir do surgimento da modernidade. Tal lacuna pode ser observada quando voltamos nosso olhar para os estudos sobre a independência do Brasil, e, conseqüentemente, das "ideologias importadas" que compõem o quadro da formação do Estado Nacional Brasileiro. Neste terreno é bastante fértil a veiculação de concepções de história informadas pela idéia de progresso. Afirma-se, em geral, que naquele momento a "pobreza ideológica" da população brasileira, em sua maioria analfabeta, "inculta" e "atrasada", constituía-se em agente deformador das idéias iluministas que chegavam ao Brasil. ${ }^{14}$ Contudo, épossivel que tais argumentos não se sustentem nem mesmo a partir da lógica de sua própria constituição interna, pois é sabido que até mesmo na França pré-revolucionária, o índice de analfabetismo da população era extremamente alto. As cidades maiores, como Paris, apresentavam cifras que talvez chegassem a $60 \%$. Aos escritos de Rousseau tinha acesso apenas uma elite alfabetizada. 0 francês comum só conseguia ter acesso a essas idéias em segunda ou terceira mãos. Nem por isso a França deixou de ser um dos países que mais criou, sistematizou e difundiu 0 ideário iluminista. ${ }^{15}$

Não se trata, pois, de vincular o analfabetismo à idéia de atraso para apontar a leitura "errada" e "deformante" que as "camadas populares" do Brasil fizeram do Iluminismo. Talvez, o caminho mais rico seja o de investigar que tipo de leitura as "camadas populares" aqui procederam, a partir de sua experiência cultural específica. Umasociedade analfabeta recobre características que remetem às especificidades da cultura oral em relação à cultura letrada. ${ }^{16}$ Neste sentido, o importante é indagar a respeito do processo que pode ter levado as "camadas populares" a re-traduzirem todo um universo intelectual da cultura letrada e, a partir de sua cultura, herdada pela transmissão oral,

\footnotetext{
${ }^{14}$ Cf. Costa, E. V. da. Da monarquia à República: Momentos Decisivos. São Paulo: Grijalbo, 1978. pp. 27s.

${ }^{15}$ Cf. Rudé, G. Ideologia e Protesto Popular. Rio de Janeiro: Zahar, 1982. p. 31 s.

${ }^{16}$ São inúmeros os trabalhos que discorrem sobre a especificidade da cultura oral em relação à cultura letrada. Vale a pena mencionar, pelo menos: Thompson, E.P. Tradicion, Revuelta y Consciência de Clase. Barcelona: Editorial Crítica, 1979. Uma das características da cultura oral, para esse autor, reside no fato de que ela está referida sobretudo a uma "sociedade analfabeta", razão pela qual a "memória popular" é aí "extraordinariamente ampla". Cf. especialmente p. 102. Para um estudo sobre a oralidade como forma específica de comunicação das sociedades tradicionais, cf. CERTEAu, M. de. "Etnographie: L'oralité ou l'espace de l'autre". In: L'écriture de l'Histoire. Paris: Gallimard, 1975. pp. 215-248.
} 
conseguir pensar diferente. ${ }^{17}$ É possível que uma abordagem de tal natureza estimule pelo menos a reflexão sobre o que foi a prática política das "camadas populares" brasileiras, a partir do resultado da complexa combinação entre suas formas "menos estruturadas de pensamento" (mitos, idéias simples, tradição) com as chamadas "ideologias derivadas" ou sistemas "mais estruturados" de idéias (Direitos do Homem, Laissez-faire, etc.).

Thompson desenvolve, de forma instigante, o problema da especificidade da cultura oral, ao estudar os movimentos pré-industriais da Inglaterra do século XVIII. No limiar da Revolução Industrial a preservação da memória significará um poderoso instrumento de luta contra a opressão imposta pelo livre-cambismo à plebe inglesa. Nos motins da fome contra o livre-cambismo a plebe exibia um modelo de conduta cuja ação central referia-se ao resgate de procedimentos de 150 anos atrás contidos no Livro de Ordens, que determinavam para os funcionários da justiça a fiscalização dos mercados para se certificarem de que eles estavam provendo os pobres dos grãos necessários e, ao mesmo tempo, fixando os preços fora das leis da livre concorrência. Thompson diz então que esta legislação de emergência se foi desmoronando durante as guerras civis. Porém a memória popular, especialmente em uma sociedade analfabeta, é extraordinariamente ampla. Pouca dúvida existe de que há uma tradição direta que se estende desde o Livro de Ordens de 1630 até os movimentos dos trabalhadores de confecção no leste e oeste da Inglaterra do século XVIII. Aqui também Thompson liberta-se da interpretação simplista segundo a qual a plebe inculta e atrasada não consegue entender as novas idéias e as novas práticas. Recorrer a práticas medievais enquanto o liberalismo plantava a semente da "modernidade" parece caracterizar, de fato, um comportamento atrasado da plebe. Porém, trata-se de interrogar, mostra Thompson, de que forma os pobres experimentaram as novas idéias na Inglaterra do período. ${ }^{18} \mathrm{Na}$ verdade, o liberalismo foi experimentado pela plebe inglesa não como progresso, mas sim como retrocesso. Os cercamentos retiraram-lhes direitos tradicionais. 0 livre-cambismo gerou uma situação de escassez profunda e fome entre os pobres. Thompson revela, enfim, que a questão do "atraso" não é tão linear. Ao procurar entender a história social do século XVIII como uma série de confrontos entre uma inovadora economia de mercado e a economia moral tradicional da plebe, o autor revela uma curiosa dialética. A plebe inglesa era tradicional em suas formas, ao recorrer a um modelo medieval de conduta. Porém,

17 Cf. análise de GinzBuRg, C. 0 queijo e os vermes: o cotidiano e as idéias de um moleiro perseguido pela Inquisição. São Paulo: Companhia das Letras, 1987.

${ }^{18}$ Cf. Thompson, E.P. 1989, Op. cit. p. 102. 
era revolucionária em seu conteúdo, ao lutar contra a opressão das novas formas sociais e políticas. É um pouco desta dialética complexa que precisamos resgatar no processo de reconstituição das lutas sociais no Brasil do século XIX.

\section{Os ESPAÇOS NÃO-INSTITUCIONAIS}

Thompson abriu caminhos instigantes para a elaboração de uma história popular, ao valorizar o estudo de seus espaços não especificamente institucionais. Ao aferirem a ação política das camadas populares a partir da referência institucional, exclusivamente, muitos historiadores acabaram minimizando aquilo que, em suas obras, anunciava-se como possibilidade fértil de recuperação da memória histórica das camadas populares, porque desconsideraram a importância de espaços de sociabilidade especificamente populares. São ainda pouco expressivas, na historiografia brasileira, as pesquisas que procuram entender a ação política das "camadas populares" a partir de espaços de sociabilidade como os vinculados às feiras, pousadas e vendas de beira de estrada. Ao estudar certos aspectos da organização e da cultura das classes subalternas da sociedade brasileira do século XIX, pudemos perceber, por exemplo, que nesses lugares entrecruzavamse tradições variadas e desenvolvia-se o exercício de negação das representações e das práticas sociais dominantes, que dava sentido às lutas sociais dos subalternos daquele período. Assim, ao apontarmos para uma abordagem que considere os diversos níveis de estruturação das "camadas populares", vamos também desfazendo a idéia da referência institucional dos partidos, das associações sindicais e da fábrica como espaços exclusivos em que poderia ocorrer a constituição do "sujeito revolucionário".

Thompson não foi, evidentemente, o único a discutir a importância de tais espaços. 0 estudo de Benjamin, por exemplo, ao analisar a boemia na Paris do século XIX, registra a relevância social e política do espaço das tabernas e critica Marx por tê-lo visto de forma depreciativa. ${ }^{19}$ Mas é de Thompson, ao estudar a classe trabalhadora inglesa do século XVIII, o trabalho mais sugestivo neste aspecto, para uma re-tematização da história das "camadas populares" do Brasil do século XIX. Este autor acentua a necessidade de estudos sobre a taberna e seus freqüentadores. Diz, ao analisar o que se escreveu sobre o trabalhador inglês: "Os que pretenderam

19 Cf. Benjamin, W. A Paris do Segundo Império em Baudelaire. In: Khote, FR. (Org.). Walter Benjamin. (Coleção Grandes Cientistas Sociais, vol. 50). São Paulo: Ática, 1985. p. 50. 
enfatizar os antecedentes constitucionais sóbrios do movimento operário por vezes minimizaram seus traços mais robustos e desordeiros. 0 que podemos fazer é ter em mente a advertência. Precisamos de mais estudos sobre as atitudes sociais dos criminosos, soldados e marinheiros, e sobre a vida de taberna; deveríamos olhar as evidências, não com olhos moralizadores (nem sempre os "pobres de Cristo" eram agradáveis), mas com olhos para os valores brechtianos - o fatalismo, a ironia em face das homilias do Establishment, a tenacidade da auto-preservação. E devemos também lembrar o "submundo" do cantor de baladas e das feiras, que transmitiu tradições para o século XIX (até o music-hall, a cultura de circo de Dickens ou os contadores de história e animadores de Hardy); pois desta forma os 'sem linguagem articulada' conservam certos valores - espontaneidade, capacidade para diversão e lealdade mútua -, apesar das pressões inibidoras de magistrados, usineiros e metodistas". ${ }^{20}$

Nesta mesma linha de ênfase aos níveis diversificados de socialização e estruturação dos subalternos, é preciso lembrar o exemplo dos moinhos, espaço similar à venda, característicos de diversas regiões e momentos da história da Europa, e que foi objeto de bastante atenção por parte de Ginzburg, ao discorrer sobre a cultura popular européia do século XVI, a partir da vida do moleiro Menocchio. São espaços como estes, analisados por Thompson, que precisam ser relevados na reconstituição da memória cultural das "camadas populares" do século XIX brasileiro. A análise desses espaços sociais pode ensejar o acesso a fragmentos importantes da vida cotidiana do homem comum. Embora não se possa libertar aqui do caráter fugidio, fragmentário e esparso que define as ideologias populares, estudar a taberna e seus freqüientadores significa dar um passo decisivo no trabalho de reconstituição da memória cultural das camadas populares do século XIX brasileiro.

\section{Rituais Populares}

Thompson devotou importante reflexão a certos rituais de protestos populares da Inglaterra do século XVIII e às suas formas ricamente diversificadas, que receberam a denominação genérica de rough music. ${ }^{21}$ Ele estudou-a por comparação com seu correspondente francês, o charivari, e, sobretudo, acompanhou com uma erudição sem

\footnotetext{
${ }^{20}$ Cf. Thompson, E. P. The Making of the English Working Class. London, Penguin Books, 1968, p. 63-64.

${ }^{21}$ Cf. Thompson, E. P. Customs in Common. New York: The New York University Press, 1991.
} 
par a migração desses rituais para várias partes da Inglaterra e suas colônias, bem como para outras partes do mundo. Pôde então interpretá-los e aferir a sua importância nas lutas populares do século XVIII, e sua dimensão como componentes expressivos do vocabulário simbólico da época. Com Thompson, entramos no universo fascinante e ao mesmo tempo complicado da decifração do significado das rough music, termo comumente usado para denotar cacofonia rude, com ou sem ritual mais elaborado, normalmente empregado para dirigir zombarias ou hostilidades contra indivíduos que desrespeitavam certas normas da comunidade.

Thompson desenvolveu uma percepção teórica bastante cuidadosa para apreender o significado das rough music, propondo um encaminhamento que negava qualquer valor a uma análise estritamente estruturalista, em que os elementos míticos do ritual se sobrepusessem ao processo social e o substituíssem pela lógica formal. Por outro lado, estava também bastante atento à desintegração das propriedades míticas do ritual, que pudesse ser ocasionada por qualquer empirismo mais afoito. Este estudo oferece algum amparo teórico e abre perspectivas imensas para a pesquisa das manifestações populares contra as formas excludentes com que as elites brasileiras encaminhavam a organização do Estado brasileiro desde fins do século XVIII.

Se os rituais vinculados às rough music inglesas e charivari franceses eram extremamente complexos e diversificados em suas formas, como reconhecia Thompson, o que dizer de formas expressivas dessa mesma natureza, que emergiam do interior de uma sociedade multirracial, como a brasileira, com elementos de vários povos e etnias compondo seu universo cultural? Trata-se, efetivamente, de um grande desafio, entender como, no amplo movimento de povos e culturas que caracterizou o nascimento da modernidade, estas formas acomodaram-se ao caldo cultural brasileiro, ganhando vida própria.

Não é difícil encontrarmos no Brasil manifestações populares com características bastante similares às rough music, estudadas por Thompson na Inglaterra do século XVIII. Em Pernambuco, os escritos de um folclorista ${ }^{22}$ nos fazem reviver os momentos que antecederam a partida de Dom Tomás, quando este deixava em 1798 o governo da Província. Naquela oportunidade ouvia-se o povo cantar em versos jocosos, o fato do Governador ter sido "chifrado" por sua amante, Dona Brites. 0 povo cantava em versos que quando Dom Tomás partira, Dona Brites aparentou chorar de tristeza, mas

22 Cf. Pereira da Costa, F. A. Anais Pernambucanos. 1795-1817. Recife, Arquivo Público Estadual - Secretaria do Interior e Justiça, 1958, vol. VI. 
disfarçadamente sorria, porque, tão logo Dom Tomás virara as costas ela já estava nos braços de Chiquinho da Ribeira, o arrematante de dízimos do mercado público do Bairro Santo Antônio, que D. Tomás construíra. Não se têm detalhes a respeito dessa zombaria hostil do povo contra seu Governador, exceto a de que os versos eram cantados com música própria. Contudo, eram versos fáceis de serem memorizados pela multidão, os chamados nominy. ${ }^{23}$ Não há também informações a respeito do acompanhamento instrumental rude e primitivo que normalmente compunha esse tipo de ritual na Inglaterra e em. outras partes do mundo em que foi encontrado. Sabendo, contudo, da forma draconiana com que o povo era tratado naquela província, é possível que essa zombaria fosse desencadeada de forma mais ou menos contida, para evitar reprimendas. De qualquer forma, tratava-se de uma manifestação popular que respondeu aos maus tratos e abusos desfechados pelo Governador, ridicularizando-o no que havia de mais sagrado numa sociedade de tipo patriarcal: a traição e a infidelidade. Estes eram temas sempre explorados quando a plebe inglesa queria hostilizar seu rei ou autoridade importante do reino, caracterizando também os rituais franceses denominados charivari.

Este ritual, zombando de D. Tomás e sua amante, tem estreita conexão com outro, que pudemos recolher do mesmo folclorista. Trata-se de um castigo imposto pelo Governador em questão a Simplício, um indivíduo do segmento social livre e sem posse da época. Por ter roubado uma tainha do viveiro do Governador, foi preso e condenado a trabalho forçado até secar o peixe furtado que trazia amarrado ao próprio pescoço. 0 crime de Simplício foi, neste episódio, considerado duplamente grave. Primeiramente, porque a ação criminal foi desencadeada contra o Governador, que personificava o poder de Estado. Em segundo lugar, o crime mereceu severa punição porque violava os preceitos judiciais burgueses relativos à propriedade privada, numa ordem social em que a mesma estava em pleno processo de constituição.

Em ambos os rituais, a publicização aparece como componente importante tanto do castigo imposto a um homem comum, quanto a hostilidade dirigida ao Governador esua amante. Trata-se de estratégias que derivam seus recursos da transmissão oral, numa sociedade que regula a sua autoridade e conduta moral por meio de formas teatrais, do espetáculo da justiça e da punição pública. É possível que o elemento da publicização dos castigos, instrumento comum das classes dominantes até inícios do século XIX, tenha se irradiado sobre a cultura popular e enriquecido seu vocabulário simbólico de contestação.

${ }^{23}$ Eram versos tão fáceis de serem memorizados como as rimas infantis e que também permitiam que se acrescentassem improvisações apropriadas à vítima e à ocasião. Cf. THompson. 1991, Op. cit. 
Mas é preciso lembrar que não apenas os folcloristas são fontes nas quais encontramos registros desses rituais. Os viajantes estrangeiros são muitas vezes as fontes primárias de que se servem os próprios folcloristas. Debret, por exemplo, recolhe detalhes preciosos de certos rituais cercados de componentes culturais e religiosos mais especificamente portugueses, como a malhação do Judas. Trata-se de um ritual encenado com efeito teatral extraordinário, animado por um grupo bastante agitado e barulhento de pessoas, entremeadas por turbilhões de fumaças e petardos detonados. Dois bonecos compõem o cenário central, um representando Judas e outro o Diabo, que serve de carrasco. Desde a vinda da Corte portuguesa, as autoridades policiais tentavam impedir os ajuntamentos em torno desses rituais, temerosas de protestos populares. Aqui também zombarias e hostilidades eram impingidas, sobretudo, contra personagens importantes do governo, como foi o caso dos rituais do sábado de Aleluia de 1831, em que vários deles foram submetidos ao simulacro do enforcamento, inclusive o ministro intendente geral e o comandante das forças militares da polícia. ${ }^{24}$

A rua era sempre o principal cenário utilizado pela população para ridicularizar personagens que se destacavam nas fileiras dos infames. 0 viajante inglês Luccock assistiu e registrou no Rio de Janeiro, rituais cuja estratégia era a de introduzir letra jocosa com o nome do indivíduo visado, em música conhecida, que se tocava geralmente pelas ruas, como, por exemplo, a que acompanhava diariamente os militares no Rio de Janeiro, quando marchavam do quartel até o palácio. 0 ridículo era aplicado de forma tão eficiente que 0 indivíduo visado às vezes perdia 0 cargo e tinha que desaparecer. Uma dessas reprimendas foi aplicada em inícios do século XIX a um ilustre membro das elites, como castigo por liderar uma reforma do catolicismo no Brasil. ${ }^{25}$

Estes não constituem os únicos exemplos de rituais de protestos que podem ser encontrados na história da participação das classes subalternas e sua coparticipação na formação do Estado e da nação no Brasil. Nem mesmo poderíamos dizer que se tratam de manifestações desconectadas umas das outras. É mais plausível concebê-las como parte da formação cultural complexa e multiforme da formação das classes trabalhadoras no Brasil.

${ }^{24}$ Cf. DeвREт, J.-B. Viagem pitoresca e bistórica ao Brasil. São Paulo/Brasília: Martins Fontes/Instituto Nacional do Livro e Ministério da Educação e Cultura, 1975. tomo II, vol. III. p. 190ss.

${ }^{25}$ Cf. Luccock, J. Notas sobre o Rio de Janeiro e partes meridionais do Brasil. (Coleção Reconquista do Brasil, vol. 21). São Paulo/Belo Horizonte: Edusp/Itatiaia, 1975. 
Por fim, é necessário enfatizar que as reflexões deste artigo não se pretendem como crítica exaustiva do percurso intelectual de Edward Thompson, nem tampouco da historiografia clássica e contemporânea do Brasil. Nosso objetivo foi muito mais explorar possibilidades que a obra de Thompson oferece para a pesquisa histórica no Brasil, algumas das quais temos abraçado como causa importante. 